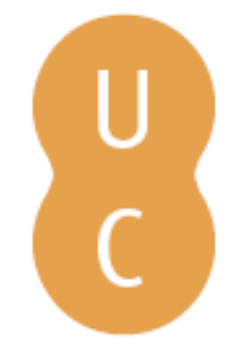

\title{
pommalina
}

\section{Comunicação, stress e estratégias de adaptação nos enfermeiros/as do Instituto Português de Oncologia de Coimbra de Francisco Gentil, epe}

\author{
Autor(es): $\quad$ Almeida, Helder \\ Publicado por: Imprensa da Universidade de Coimbra \\ URL \\ persistente: URI:http://hdl.handle.net/10316.2/36633 \\ DOI: $\quad$ DOI:http://dx.doi.org/10.14195/978-989-26-0968-3_4 \\ Accessed : $\quad$ 26-Apr-2023 10:48:44
}

A navegação consulta e descarregamento dos títulos inseridos nas Bibliotecas Digitais UC Digitalis, UC Pombalina e UC Impactum, pressupõem a aceitação plena e sem reservas dos Termos e Condições de Uso destas Bibliotecas Digitais, disponíveis em https://digitalis.uc.pt/pt-pt/termos.

Conforme exposto nos referidos Termos e Condições de Uso, o descarregamento de títulos de acesso restrito requer uma licença válida de autorização devendo o utilizador aceder ao(s) documento(s) a partir de um endereço de IP da instituição detentora da supramencionada licença.

Ao utilizador é apenas permitido o descarregamento para uso pessoal, pelo que o emprego do(s) título(s) descarregado(s) para outro fim, designadamente comercial, carece de autorização do respetivo autor ou editor da obra.

Na medida em que todas as obras da UC Digitalis se encontram protegidas pelo Código do Direito de Autor e Direitos Conexos e demais legislação aplicável, toda a cópia, parcial ou total, deste documento, nos casos em que é legalmente admitida, deverá conter ou fazer-se acompanhar por este aviso.

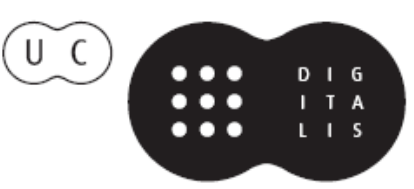




\section{CADERNOS DE PSIOUIATRIA SOCIAL E CULTURAL}

\section{\# 0}

MANUEL JOÃO QUARTILHO (COORD.)

HELDER ALMEIDA

ISABEL FAZENDA

ISABEL GIL

LINDA FERNANDES

MARIA DE FÁTIMA SOUSA

NUNO CARRILHO

RITA ALCAIRE

IMPRENSA DA UNIVERSIDADE DE COIMBRA COIMBRA UNIVERSITY PRESS 
Comunicação, stress e estratégias de adaptação em enfermeiros/as do Instituto Português de Oncologia de Coimbra de Francisco Gentil, epe 


\section{Helder Almeida ${ }^{21}$}

Instituto Português de Oncologia de Coimbra de Francisco Gentil, EPE

\section{Resumo}

A influência do comportamento comunicacional assertivo no cuidar serviu de mote para a realização deste trabalho. Pretendeu-se ainda estudar a influência da vulnerabilidade ao stress, as estratégias de adaptação e o apoio social percebido na adopção do comportamento comunicacional assertivo com os doentes e equipa multidisciplinar. O estudo do burnout também foi tido em conta devido ao papel que este pode ter no comportamento adoptado pelo/a enfermeiro/a. O estudo é descritivo-correlacional e tem como objectivo caracterizar o comportamento comunicacional assertivo dos/as enfermeiros/as nas relações interpessoais/equipa, identificar situações de burnout; analisar as estratégias de adaptação ao stress e relacionar as variáveis sociodemográficas e profissionais com as características estudadas. A população em estudo é composta pela totalidade de enfermeiros/as do IPOC-FG, EPE que trabalham nos internamentos e ambulatório, perfazendo um total de 237 indivíduos. A amostra é composta por 129 enfermeiros/as que responderam ao questionário correctamente.

O estudo do comportamento comunicacional assertivo foi preponderante nesta investigação. Os/as enfermeiros/as apresentam comportamento comunicacional assertivo com elevada frequência. Este é adoptado com mais frequência com os doentes do que no seio da equipa multidisciplinar, daí a assertividade ser essencial para o bom ambiente de trabalho e nas relações interpessoais. O estudo mostra que há um valor alto de realização pessoal, baixo de despersonalização e médio de exaustão emocional. Entenda-se a despersonalização como um distanciamento face à relação, de modo a evitar um envolvimento nos problemas dos outros não afectando assim a vida pessoal do enfermeiro. Encontrámos nos homens mais despersonalização do que nas mulheres, o que sugere um afastamento nas ligações, não se envolvendo demasiado como forma de não levar os problemas do hospital para casa.

Um dado novo prende-se com a adopção de comportamento comunicacional assertivo e o facto de se ter um duplo emprego. Os/as enfermeiros/as que referem ter um duplo emprego apresentam com menos frequência comportamento comunicacional assertivo.

O facto de se trabalhar por turnos mostrou também o seu interesse no presente estudo, uma vez que se verificou que quem faz turnos adopta com menos frequência comportamento comunicacional assertivo do que quem tem horário fixo.

Quanto à vulnerabilidade ao stress o estudo sugere que os/as enfermeiros/as mais novos/as são mais propensos/as, podendo estar relacionado com o facto de terem pouca autonomia, das suas expectativas, do vínculo precário e dificuldades na prestação de cuidados.

21 Mestre em Psiquiatria Cultural e enfermeiro graduado do IPOCFG, EPE. 
Encontraram-se ainda relações entre género, estado civil e experiência profissional com as outras variáveis em estudo, sendo importantes para as conclusões desta investigação.

Palavras chave: Comportamento comunicacional assertivo, Stress, Burnout, Coping, Apoio social, Enfermeiros.

\section{Abstract}

The influence of assertive communication behavior in care served as a motto for this work. The aim was also to study the influence vulnerability to stress, coping strategies and perceived social support in the adoption of assertive communication behavior with patients and multidisciplinary team. The study of burnout was also taken into account due to the role it may have on the behavior adopted by nurse.

The study is descriptive - correlational and aims to characterize the behavior of assertive communication of nurses in the interpersonal team relationships, identify situations of burnout; analyze the strategies of adaptation to stress and relate professionals with sociodemographic characteristics studied variables. The study population is composed of all nurses the IPOC - FG EPE working in inpatient and outpatient, for a total of 237 individuals. The sample comprised 129 nurses who responded to the questionnaire correctly.

The study of assertive communication behaviour was prevalent in this investigation. The nurses demonstrate assertive communication behaviour at high frequency. This is adopted more frequently to patients than within the multidisciplinary team, then assertiveness is essential for and adequate work environment and interpersonal relationships.

The study shows that there is a high value of personal accomplishment, low depersonalization and average emotional exhaustion. It is important to observe depersonalizations as a distancing from the relationship, avoiding involvement in the problems of others thereby are not affecting the personal lives of nurses. We found more depersonalization in men than in women, suggesting a withdraw in attachment, not involving too much as a way to not taking the problems from the hospital to home. A new data relates the adoption of assertive communication behaviour and the fact of having a double employment. The nurses who reported having a double employment often demonstrates less rates of assertive communication behaviour.

The fact of working by shifts has also interest in this study, because anyone who works by shifts, demonstrated more often less assertive communication behaviour than those with fixed schedule. The vulnerability to stress in the study suggests that younger nurses are more likely to trend, and that may be related with a limited autonomy, expectations, precarious bond and difficulties in providing care. The study also revealed relations between gender, marital status and professional experience with the other variables present in this study, and they become important for these findings.

Keywords: communication Assertive Behavior, Stress, Burnout, Coping, Social Support, Nurse. 


\section{Introdução 22}

A enfermagem centra-se no Cuidar. O cuidar engloba todas as actividades essenciais de forma a prevenir a doença, promover e restabelecer a saúde. No entanto, o que é visível aos olhos de todos é o alívio dos sintomas físicos, mas cuidar é muito mais do que isto.

A relação de ajuda e a comunicação interpessoal são a base de todo um processo de cuidados de saúde. A pouca visibilidade destes secundariza-os, mas no fundo, são os mais importantes.

Walter Hesbeen (2000) referindo-se aos cuidados de enfermagem diz que não são espectaculares, não são observáveis e mensuráveis, ou são-no tão pouco que não gozam da aura que rodeia os cientistas e os técnicos, cuja actividade é identificável e observável, o que lhes dá prestígio, daí a necessidade de identificar resultados sensíveis aos cuidados de enfermagem.

O cuidar implica proximidade, estar próximo de quem precisa de uma palavra ou fazer um desabafo e de quem muitas vezes sofre em silêncio.

A proximidade com o doente oncológico não será indiferente à acção dos profissionais de enfermagem. O envolvimento causa desgaste emocional e físico e também estes necessitarão de alguma forma de apoio.

O stress em enfermeiros é um problema que tem despertado alguma atenção, mas que infelizmente, não tem tido a relevância necessária junto das instituições. Este é muitas vezes silencioso e só o agravar dos sintomas o pode tornar visível. A incapacidade de lidar com situações de stress pode degenerar num esgotamento físico e emocional, denominado Síndrome de Burnout. O suporte que os/as enfermeiros/as têm dentro ou fora da instituição será também relevante na condução das suas relações. As estratégias de adaptação, nem sempre são as mais adequadas e eficazes, mas também podem ser funcionais e prevenir todo um processo de stress.

Compreender as características de comunicação dos/as enfermeiros/as quando trabalham com doentes oncológicos e o nível do stress e as suas capacidades de gestão do mesmo, foi o ponto de partida para esta investigação.

As conclusões emergentes do trabalho poderão ser úteis na gestão dos serviços de enfermagem, nomeadamente na contratação de pessoal, assim como na rotatividade pelos diferentes serviços. Poderá ainda ajudar a traçar um perfil para determinados serviços, onde a proximidade com o doente é maior e a tendência para desenvolver stress poderá estar mais presente.

22 Texto realizado com base na tese de mestrado "Comunicação, Stress e Estratégias de Adaptação nos Enfermeiros/as do Instituto Português de Oncologia de Coimbra de Francisco Gentil, EPE" no âmbito do I Mestrado em Psiquiatria Cultural da Faculdade de Medicina da Universidade de Coimbra, orientada pelo Professor Doutor José Carlos Santos e coorientada pelo Professor Doutor Carlos Braz Saraiva 


\section{Metodologia}

\section{Tipo de estudo}

Este trabalho é um estudo descritivo-correlacional, em que, segundo Marie-Fabienne Fortin (1999: 174), "o investigador explora e determina a existência de relações entre variáveis com vista a descrever essas relações". Acrescenta que o objectivo deste estudo é a descoberta de factores ligados ao fenómeno. Refere ainda que "permite, no decorrer do mesmo processo, considerar simultaneamente várias variáveis com vista a explorar as suas relações mútuas" (idem).

\section{Procedimentos Éticos}

Foi realizado o pedido formal, e autorizado o estudo pelo Conselho de Administração do IPOC-FG, EPE, dando a conhecer a investigação que se pretende realizar e garantindo o cumprimento de todos os pressupostos éticos relativos a uma investigação científica.

Os participantes podem actualmente ter acesso aos resultados da investigação.

Foram ainda pedidos os instrumentos aos respectivos autores, que por escrito autorizaram a sua utilização, ficando salvaguardado o direito de autor.

TABELA 1

CARACTERÍSTICAS DEMOGRÁFICAS E PROFISSIONAIS DA AMOSTRA

\begin{tabular}{|c|c|c|c|c|c|}
\hline \multicolumn{2}{|c|}{ Variáveis demográficas/profissionais } & $\mathbf{N}$ & $\%$ & Média & $\begin{array}{l}\text { Desvio } \\
\text { padrão }\end{array}$ \\
\hline \multicolumn{2}{|l|}{ Idade } & 129 & & 35,07 & 8,851 \\
\hline \multirow{2}{*}{ Género } & Masculino & 29 & 22,5 & & \\
\hline & Feminino & 100 & 77,5 & & \\
\hline \multirow{2}{*}{ Estado Civil } & Não casado & 59 & 38,8 & & \\
\hline & Casado & 79 & 61,2 & & \\
\hline \multirow{3}{*}{ Residência } & Urbano & 73 & 56,6 & & \\
\hline & Periferia & 44 & 34,1 & & \\
\hline & Rural & 12 & 9,3 & & \\
\hline \multirow{2}{*}{ Religião } & Católico & 114 & 88,4 & & \\
\hline & Outras & 15 & 11,6 & & \\
\hline \multirow{2}{*}{$\begin{array}{l}\text { Características do } \\
\text { serviço }\end{array}$} & Internamento & 99 & 76,7 & & \\
\hline & Ambulatório & 30 & 23,3 & & \\
\hline \multirow{2}{*}{ Habilitações } & Bacharelato & 19 & 14,7 & & \\
\hline & Licenciatura & 110 & 85,3 & & \\
\hline \multirow{4}{*}{$\begin{array}{l}\text { Categoria } \\
\text { profissional }\end{array}$} & Enfermeiro & 45 & 34,9 & & \\
\hline & Graduado & 71 & 55,0 & & \\
\hline & Especialista & 8 & 6,2 & & \\
\hline & Chefe & 5 & 3,9 & & \\
\hline \multirow{2}{*}{$\begin{array}{l}\text { Regime de } \\
\text { trabalho }\end{array}$} & Turnos & 84 & 65,1 & & \\
\hline & Fixo & 45 & 34,9 & & \\
\hline \multirow{2}{*}{ Duplo emprego } & Sim & 28 & 21,7 & & \\
\hline & Não & 101 & 78,3 & & \\
\hline \multirow{2}{*}{ Vínculo } & Quadro & 88 & 68,2 & & \\
\hline & Contrato & 41 & 31,8 & & \\
\hline $\begin{array}{l}\text { Experiência } \\
\text { profissional }\end{array}$ & & 129 & & $\begin{array}{c}148,45 \text { (meses) } \\
12,37 \text { (anos) }\end{array}$ & 103,393 \\
\hline
\end{tabular}




\section{Instrumentos De Colheita De Dados}

Escala de Avaliação dos Comportamentos Assertivos dos Enfermeiros - Jesus, S. N. e Amaro, H. J. F (2005)

A Escala de Avaliação dos Comportamentos Assertivos dos Enfermeiros é constituída por duas sub-escalas.

A Sub-escala A: Comportamentos Assertivos com os Utentes é constituída por seis itens, em que se obteve um alpha de Cronbach de 0.7608. Relativamente à Sub-escala B: Comportamentos Assertivos com a Equipa Multidisciplinar, é constituída por 18 itens, tendo-se obtido um alpha de Cronbach de 0.8954. No que diz respeito à Escala de Comportamentos Assertivos do Enfermeiro, obteve-se um alpha de Cronbach de 0.8980, o que para Hill e Hill (2005) corresponde a um alpha bom.

É usada uma Escala de tipo likert de seis pontos, sendo (1) Nunca e (6) Sempre.

\section{Escala para avaliar a vulnerabilidade ao stress (23 QVS) - Vaz Serra (2000)}

Escala de tipo likert de cinco pontos, com cotação de 0 a 4 (itens 1,3,4,6,7,8,20) e (inversa nos itens $2,5,9,10,11,12,13,14,15,16,17,18,19,21,22,23)$. Foi realizada uma revisão da literatura com 64 questões. Numa Investigação com $(n=368)$, efectuou-se uma selecção de 23 itens, apresentando uma elevada correlação item-total (>0.20) (homogeneidade/unidimensionalidade da escala). O coeficiente alpha de Cronbach =0.824 (consistência Interna) e Correlação teste-reteste (49 dias; $n=105)=0.816$ (estabilidade temporal). A escala encontra-se dividida em sete factores, sendo eles por ordem crescente:

Factor 1 - Perfeccionismo e intolerância à frustração (itens 5,10,16,18,19,23)

Factor 2 - Inibição e dependência funcional (itens 1,2,9,12,22)

Factor 3 - Carência de apoio social (itens 3,6)

Factor 4 - Condições de vida adversas (itens 4,21)

Factor 5 - Dramatização da existência (itens 5,8,20)

Factor 6 - Subjugação (itens 11,13,14,15)

Factor 7 - Deprivação de afecto e rejeição (itens $7,13,17$ )

Há uma correlação positiva com neuroticismo (EPI) e negativa com a capacidade de resolução de problemas (IRP).

Questionário de Apoio Social (SSQ) - Sarason, I.; Sarason, B. \& Pierce, G., 1987; Versão portuguesa de Pinheiro, M. \& Ferreira, J. (2000)

O Questionário de Apoio Social (SSQ) é uma escala de auto-aplicação concebida para quantificar a disponibilidade e o grau de satisfação com o apoio social percebidos. Cada uma das perguntas 
requer uma resposta em dois momentos: pede-se aos inquiridos que enumerem primeiro até nove pessoas para quem acham que se podem virar e em quem confiem em circunstâncias concretas de necessidade (1); e depois que pontuem, recorrendo a uma escala graduada em seis pontos entre muito satisfeito e muito insatisfeito, em que medida se sentem satisfeitos com o apoio disponível (2).

A tradução portuguesa da versão abreviada, tal como usada neste estudo, apresentou um alpha para a disponibilidade de 0.89 , e um alpha para a satisfação de 0.88 .

\section{Inventário de Resolução de Problemas (Vaz Serra, 1988)}

O inventário de resolução de problemas consiste numa escala de auto-avaliação constituída por 40 questões, a qual permite obter uma nota global e valores informativos relativos a nove subescalas: pedido de ajuda, confronto e resolução activa dos problemas, abandono passivo, controlo internolexterno dos problemas, estratégias de controlo das emoções, atitude activa de não interferência da vida quotidiana pelas ocorrências, agressividade internalizada/externalizada, auto-responsabilização e medo das consequências, confronto com o problema e planificação da estratégia.

Esta escala apresenta um coeficiente de Sperman-Brown de 0.860, demonstrando boa estabilidade temporal e uma correlação teste-reteste de $0.808(n=102), p<0,001$.

Maslach Burnout Inventory (MBI) - Maslach e Jackson (1986); Nunes (1996).

Escala de tipo likert de sete pontos (de $0=$ nunca a $6=$ todos os dias), com 22 itens, distribuídos por três sub-escalas:

Exaustão emocional (itens 1,2,3,6,8,13,14,16,20)

Despersonalização (itens 5,10,11,15,22)

Realização profissional $(4,7,9,12,17,18,19,21)$

\section{Questionário de características sócio-demográficas}

Constituído por Idade, Género, Estado Civil, Residência, Religião, Característica do serviço, Habilitações Literárias, Categoria Profissional, Regime de Trabalho, Duplo Emprego, Vínculo, Experiência Profissional.

\section{Resultados}

A população em estudo caracteriza-se por uma baixa vulnerabilidade ao stress com uma média de 1,56 [0-4], um burnout médio de 2,76 [0-6], estratégias de adaptação ao stress/coping na ordem dos 3,86 de média [1-5] e um comportamento comunicacional assertivo com elevada frequência 4,97 de média [1-6]. Apresenta ainda grande satisfação com o apoio social percebido com uma média de 5,17 [1-6]. 
TABELA 2

QUADRO GERAL DAS CORRELAÇÕES ENTRE AS ESCALAS UTILZADAS NO ESTUDO

\begin{tabular}{|c|c|c|c|c|c|c|c|c|c|}
\hline Escalas & & QVS & $\mathrm{MBI}$ & SSQQ & SSQS & IRP & ecea & Eceb & ecetotal \\
\hline \multirow{3}{*}{$\begin{array}{l}\text { Vulnerabilidade } \\
\text { ao stress (QVS) }\end{array}$} & $R$ & 1,000 &, $174^{*}$ &,- 029 &,$- 230^{* *}$ &,$- 477^{* *}$ &, 001 &,$- 295^{* *}$ &,$- 178^{*}$ \\
\hline & $P$ & &, 049 & ,744 &, 009 &, 000 & ,992 &, 001 &, 044 \\
\hline & $\mathrm{N}$ & 129 & 129 & 129 & 129 & 129 & 129 & 129 & 129 \\
\hline \multirow{3}{*}{$\begin{array}{l}\text { Burnout } \\
\qquad \mathrm{MBI}\end{array}$} & $R$ &, $174^{*}$ & 1,000 & $187^{*}$ &, 048 &,$- 218^{*}$ &,- 112 &, 022 &,- 049 \\
\hline & $P$ &, 049 & &, 034 &, 589 &, 013 & 205 & 802 &, 579 \\
\hline & $\mathrm{N}$ & 129 & 129,000 & 129 & 129 & 129 & 129 & 129 & 129 \\
\hline \multirow{3}{*}{$\begin{array}{l}\text { Quantidade de apoio social } \\
\text { percebido (SSQQ) }\end{array}$} & $\mathrm{R}$ &,- 029 &, $187^{*}$ & 1,000 & $281^{* *}$ &,- 129 &,- 129 &,- 056 &,- 106 \\
\hline & $P$ & ,744 &, 034 & &, 001 &, 144 &, 144 &, 527 & ,231 \\
\hline & $\mathrm{N}$ & 129 & 129 & 129,000 & 129 & 129 & 129 & 129 & 129 \\
\hline \multirow{3}{*}{$\begin{array}{c}\text { Satisfação com o apoio social } \\
\text { percebido (SSQS) }\end{array}$} & $R$ &,$- 230^{* *}$ &, 048 &, $281^{* *}$ & 1,000 & , 144 &,- 145 &, 042 &,- 056 \\
\hline & $P$ &, 009 &, 589 &, 001 & &, 103 &, 100 & 633 &, 531 \\
\hline & $\mathrm{N}$ & 129 & 129 & 129 & 129,000 & 129 & 129 & 129 & 129 \\
\hline \multirow{3}{*}{$\begin{array}{c}\text { Estratégias de adaptação ao } \\
\text { stress (IRP) }\end{array}$} & $R$ &,$- 477^{* *}$ &,$- 218^{*}$ &,- 129 &, 144 & 1,000 & ,086 & $335^{* *}$ & $250^{* *}$ \\
\hline & $P$ &, 000 &, 013 &, 144 &, 103 & & ,331 &, 000 &, 004 \\
\hline & $\mathrm{N}$ & 129 & 129 & 129 & 129 & 129,000 & 129 & 129 & 129 \\
\hline \multirow{3}{*}{$\begin{array}{l}\text { Comportamento comunicacional } \\
\text { assertivo com utentes (ECEA) }\end{array}$} & $\mathrm{R}$ & ,001 &, 022 &,- 129 &,- 145 &, 086 & 1,000 & $481^{* *}$ & $849^{* *}$ \\
\hline & $P$ & ,992 & ,205 &, 144 &, 100 & ,331 & &, 000 &, 000 \\
\hline & $\mathrm{N}$ & 129 & 129 & 129 & 129 & 129 & 129,000 & 129 & 129 \\
\hline \multirow{3}{*}{$\begin{array}{l}\text { Comportamento comunicacional } \\
\text { assertivo com equipa (ECEB) }\end{array}$} & $R$ &,$- 295^{\star *}$ &, 022 &,- 056 &, 042 &, $335^{* *}$ &, $481^{* *}$ & 1,000 & $872^{* *}$ \\
\hline & $P$ &, 001 &, 802 &, 527 &, 633 &, 000 &, 000 & &, 000 \\
\hline & $\mathrm{N}$ & 129 & 129 & 129 & 129 & 129 & 129 & 129,000 & 129 \\
\hline \multirow{3}{*}{$\begin{array}{l}\text { Comportamento comunicacional } \\
\text { assertivo total (ECEtotal) }\end{array}$} & $R$ &,$- 178^{*}$ &,- 049 &,- 106 &,- 056 & $250^{* *}$ & $849^{* *}$ & $872^{* *}$ & 1,000 \\
\hline & $P$ &, 044 &, 579 & ,231 &, 531 &, 004 &, 000 &, 000 & \\
\hline & $\mathrm{N}$ & 129 & 129 & 129 & 129 & 129 & 129 & 129 & 129,000 \\
\hline
\end{tabular}

\section{Discussão}

A discussão deste estudo passa por apresentar os dados encontrados e tentar explicá-los tendo como base uma revisão bibliográfica e resultados de outros estudos realizados sobre a mesma temática.

O estudo do comportamento comunicacional assertivo nos enfermeiros/as encontra-se ainda pouco explorado, no entanto Jesus e Amaro (2005) realizaram uma investigação e validaram as escalas utilizadas neste estudo.

Os resultados do presente estudo indiciam que os/as enfermeiros/as adoptam comportamentos assertivos com elevada frequência, sendo que a média do comportamento assertivo com os doentes é superior à dos comportamentos assertivos com a equipa multidisciplinar. Estes resultados vão ao encontro aos estudos de Saul Jesus e Hugo Amaro (2005).

Não se encontra qualquer relação entre característica do serviço e comportamento comunicacional assertivo, não se confirmando a hipótese apontada. Quer os enfermeiros do internamento quer os do ambulatório apresentam comportamento comunicacional assertivo com elevada frequência.

Na relação entre os comportamentos comunicacionais assertivos e o burnout não se encontraram resultados estatísticos significativos, tal como em Jesus e Amaro (2005). Não se confirma a hipótese levantada no nosso estudo que sugere uma relação entre o comportamento comunicacional assertivo e o burnout.

Numa análise entre a escala do comportamento assertivo e as dimensões do burnout verificou-se uma correlação positiva entre comportamento assertivo total e realização pessoal e uma correlação negativa entre comportamento comunicacional assertivo total e a despersonalização. O bom ambiente no trabalho e a adopção de comportamentos comunicacionais assertivos com bastante frequência, influenciam de forma positiva a realização profissional, como sugerem os estudos de Maslach e 
Jackson (2001), Paulo Queirós (2004) e Saul Jesus (2005). Na sequência dos resultados é de esperar que a despersonalização apresente uma média baixa uma vez que se o/a enfermeiro/a se sente profissionalmente realizado é porque tem sucesso nas suas relações interpessoais, quer com os doentes quer com a equipa multidisciplinar. Entenda-se a despersonalização como um distanciamento face a relação, de modo a evitar um envolvimento nos problemas dos outros não afectando assim a vida pessoal do enfermeiro.

Não se encontrou no entanto qualquer relação com a exaustão emocional, apresentando esta dimensão uma média baixa indo ao encontro do estudo realizado por Pacheco e Jesus (2007). Este resultado sugere que os enfermeiros adoptam estratégias de adaptação ao stress adequadas e eficazes, reforçado pelo mesmo estudo atrás citado. Encontrámos no estudo uma correlação negativa entre burnout e estratégias de adaptação ao stress, fortalecendo o que já foi referido e confirmando a hipótese levantada, que indiciava essa mesma correlação.

Foi ainda encontrada uma relação entre burnout e apoio social percebido, como tinha sido sugerido por uma das hipóteses do estudo. Existe assim uma correlação positiva entre burnout e a quantidade de apoio social percebido, não havendo qualquer relação relativamente à satisfação com esse apoio. Os/as enfermeiros/as que apresentam mais burnout, referem ter a percepção de uma maior rede de apoio social disponível.

Na continuação da análise dos resultados do nosso estudo, verifica-se que estes/as enfermeiros/as, ao apresentarem comportamentos assertivos com elevada frequência, é expectável que demonstram uma vulnerabilidade ao stress baixa, o que se veio a verificar. Confirmou-se assim a hipótese levantada no nosso estudo que sugeria uma correlação negativa entre comportamento comunicacional assertivo e vulnerabilidade ao stress. Encontra-se uma correlação negativa com a inibição e dependência funcional e com a deprivação de afecto e com a rejeição. Depreende-se que os/as enfermeiros/as se encontram com estabilidade no trabalho, realizados com o que fazem e que possuem uma rede de apoio social que dá resposta às suas necessidades. Verifica-se neste estudo uma correlação negativa entre vulnerabilidade ao stress e estratégias de adaptação e também com o apoio social percebido, ou seja, os/as enfermeiros/as apresentam baixa vulnerabilidade ao stress e boas estratégias de adaptação e ainda uma percepção de apoio social satisfatória.

Relativamente às estratégias de adaptação ao stress os/as enfermeiros/as do estudo apresentam um valor médio alto. Em relação à escala de comportamento comunicacional assertivo encontra-se uma correlação positiva com a escala total e com o comportamento comunicacional assertivo com a equipa multidisciplinar. Os enfermeiros que apresentam comportamento comunicacional assertivo com mais frequência adoptam mais estratégias de adaptação ao stress.

Verifica-se ainda uma correlação positiva entre a escala de comportamento assertivo total e as dimensões confronto e resolução activa dos problemas e confronto com o problema e planificação da estratégia. Estes resultados vão ao encontro do estudo de Elsa Silva (2005) que chegou à conclusão que os/as enfermeiros/as com mais anos idade utilizam com mais frequência estratégias de coping de auto-controlo. Refere ainda que os/as enfermeiros/as com menos anos no serviço recorriam 
mais frequentemente a estratégias de resolução planeada do problema e os/as enfermeiros/as mais antigos/as utilizavam com mais frequência a estratégia de coping confrontativo. Já no estudo de Pacheco e Jesus (2007) a gestão dos sintomas é a estratégia mais utilizada seguida do controlo e por fim o escape perante a situação problema. No entanto, apesar do seu interesse, não se podem comparar "totalmente" os resultados deste estudo com o nosso, uma vez que se trata de escalas e dimensões diferentes.

Encontra-se ainda uma correlação negativa entre comportamento comunicacional assertivo e a dimensão pedido de ajuda. Este resultado poderá estar associado à realização profissional e à percepção de apoio social que os enfermeiros referem como satisfatória.

Quanto ao apoio social percebido, os/as enfermeiros/as referem estar satisfeitos/as, havendo uma correlação positiva entre quantidade e qualidade desse apoio. A rede de apoio percebida pode não corresponder à realidade uma vez que trabalhamos com percepções. Apenas ficamos a saber o que temos quando precisamos verdadeiramente. Há ainda uma cultura "enraizada" de que podemos contar com toda a gente em nosso redor. Devido a este peso cultural, era de esperar estes resultados.

Quanto ao género não se verifica uma diferença estatisticamente significativa em relação ao burnout. No entanto, os homens apresentam uma média de burnout superior. Não se confirma a nossa hipótese que sugere uma relação entre género e burnout. Estes resultados não confirmam os descritos por Dirkx (1991) citado por Paulo Queirós (2004) que refere o duplo papel das mulheres como causa para níveis mais altos de burnout. No entanto, verifica-se uma correlação positiva entre o género masculino e a despersonalização. Os homens apresentam uma média superior às mulheres no que diz respeito à dimensão despersonalização, sendo esta estatisticamente significativa, o que reforça os resultados encontrados por Christina Maslach (1981) em que as mulheres apresentam níveis mais baixos de despersonalização do que os homens. Dionísia Loreto (2000) também refere que o género masculino se relaciona ligeiramente com a "despersonalização". Os resultados sugerem que os homens não se envolvem tanto nas ligações como forma de separar a vida hospitalar da pessoal. Já no que diz respeito à dimensão exaustão emocional e realização profissional, o nosso estudo não confirma os achados de Maslach (1981), que refere que as mulheres apresentam níveis mais altos de exaustão emocional e mais baixos de realização profissional. Encontrámos no presente estudo uma maior exaustão emocional e uma menor realização profissional relativamente aos homens.

Já Arlette Germay (2006) citado por Michel Debrouck (2006: 214) diz que "as mulheres correm 1,6 vezes mais risco de exaustão do que os homens". No entanto, "as que têm filhos, têm 40\% menos probabilidade de desenvolver uma exaustão". A variável "filhos" não foi estudada no presente estudo, daí não poder haver comparação, ficando contudo a diferença relativamente à dimensão exaustão emocional nos homens.

Relativamente à característica do serviço, não se encontram diferenças significativas. O facto de trabalhar no ambulatório ou no internamento parece não ser relevante neste estudo. Estes resultados vão ao encontro do estudo de Loreto (2000) que ao estudar enfermeiros de oncologia não encontrou 
diferença significativa de burnout entre os que trabalham nos serviços de internamento e os do ambulatório. Estes resultados podem dever-se a uma política institucional de integração e a um plano de formação igual para todos os colaboradores funcionando como uma estratégia de envolver todos os profissionais na missão e filosofia da instituição. De referir ainda alguma rotatividade de enfermeiros/ as entre serviços, daí que muitos dos que estão no ambulatório já trabalharam no internamento e vice-versa. O tamanho da instituição e o reduzido número de profissionais é também relevante, uma vez que quase todos se conhecem e interagem com elevada frequência.

Quanto ao estado civil, optou-se por agrupar os enfermeiros/as que referiram serem solteiros/ as, viúvos/as e divorciados/as, comparando-os/as com os/as enfermeiros/as que referiram serem casados/as. Esta opção pareceu-nos determinante, pois o facto de não ter uma relação assumida pode sugerir uma maior probabilidade de viver sozinho. Foi encontrada uma correlação positiva entre as estratégias de adaptação ao stress e o burnout com o estado civil casado/a. Estes resultados vão ao encontro dos estudos de I. M. Garcia (1990) que refere que o estar casado/a parece estar associado a níveis mais baixos de burnout. Também Rene Mendes (1995) refere que estar casado é indicativo de maior satisfação profissional. Confirma-se assim a hipótese sugerida que prevê uma relação entre o estado civil e o burnout.

Quem não é casado/a apresenta mais burnout e menos estratégias de adaptação ao stress do que quem é casado/a. O facto de se estar casado/a pode indicar uma rede de apoio social maior e mais satisfatória, assim como melhores estratégias de adaptação que permitem enfrentar o stress de forma mais adequada e daí resultar menos burnout do que nas pessoas que potencialmente vivem sós. Num estudo realizado por Elsa Silva (2005) sobre as estratégias de coping utilizadas pelos enfermeiros/as, verificou que os/as casados/as utilizam com maior frequência estratégias de adaptação ao stress que os/as solteiros/as. Em vários estudos se tem revelado a importância da família como base de ajuda (Vaz Serra, 2007).

Há uma correlação positiva entre regime de trabalho e comportamento comunicacional assertivo. Quem faz turnos apresenta comportamento comunicacional assertivo com menor frequência. Os enfermeiros que trabalham por turnos evidenciam alterações a nível comportamental, adoptando com menos frequência comportamento comunicacional assertivo. Confirma-se a hipótese que sugere uma correlação negativa entre trabalho por turnos e comportamento comunicacional assertivo. Vaz Serra (2007) refere que o facto de se trabalhar por turnos altera o ritmo circadiano e isso tem influência directa nos aspectos biológicos e emocionais do indivíduo, como a tolerância, a paciência, a capacidade de concentração e o raciocínio. Acrescenta que estes indivíduos sentem-se cansados, sonolentos e desmotivados. Estes factos vêm comprovar os resultados, pois existe uma correlação negativa entre despersonalização e comportamento comunicacional assertivo.

Já no que diz respeito ao regime de trabalho e burnout, não se verifica qualquer relação, não se confirmando os resultados dos estudos de Jesus e Amaro (2005) que demonstraram haver diferenças entre o trabalho por turnos e o burnout, mais concretamente nas dimensões despersonalização e realização profissional. Os enfermeiros que trabalham por turnos apresentam valores médios de 
despersonalização mais elevados, enquanto que na dimensão realização profissional, os valores mais elevados foram obtidos pelos enfermeiros que não trabalham por turnos.

Há no entanto um estudo realizado por Martins e Martins (1999) que refere que os sujeitos que trabalhavam por turnos e aqueles que faziam regime de horário fixo não apresentaram diferenças quanto à satisfação com a quantidade de tempo livre para dedicarem à vida social e doméstica, dados não confirmados no nosso estudo.

Há uma correlação positiva entre vínculo e quantidade de apoio social percebido. Os enfermeiros contratados referem uma maior quantidade de apoio social percebido que os do quadro.

Estes resultados podem evidenciar que os enfermeiros mais novos ainda dependem dos pais, e vêem-nos como suporte, ao contrário dos enfermeiros mais velhos que podem ter filhos ao seu encargo e como refere Ana Paula Relvas (1996) o casal pode ver-se a cargo com o cuidar dos seus próprios pais idosos, doentes e dependentes. Pode ainda ser reforçado pela chamada crise do "ninho vazio" descrito como uma nova fase para a família. No entanto, Relvas (1996) considera esta crise mais como um "mito colectivo" do que uma experiência da vida real. Supõem-se que com a saída dos filhos de casa, os casais se voltem a encontrar e a reatar uma vida a dois tendo de construir uma nova realidade, ajustada ao interesse de ambos.

Talbot Y, Christie-Seely J, Charbonneau S. (1984), referem que na realidade actual, perante a grande mobilidade geográfica que existe, há barreiras físicas impostas pelas distâncias que separam as famílias. Este facto pode impedir que este apoio aos idosos isolados se concretize. A resolução passa por alargar e enriquecer a rede de suporte social.

O vínculo com a instituição parece ainda apresentar alguma influência no tipo de comportamento, como referem Jesus e Amaro (2005) no seu estudo, onde verificaram que os enfermeiros que possuem um vínculo laboral ao quadro da instituição são aqueles que adoptam comportamentos assertivos com maior frequência. Esta relação sugere ser importante na redução do stress.

A noção de segurança permite ao enfermeiro idealizar projectos que não seriam possíveis se o vínculo se mantiver precário. No entanto não foi encontrada qualquer relação no presente estudo entre vínculo e comportamento comunicacional assertivo. Este dado poderá ser apoiado pela filosofia da instituição e de integração, onde não se verificam diferenças entre os enfermeiros contratados e os do quadro. Outra explicação plausível poderá ser a uniformização dos contratos, onde a "figura" do "quadro" deixa de fazer sentido e todos os enfermeiros passam a ter contratos idênticos.

Como refere Vaz Serra (2007) a insegurança sentida com a manutenção do emprego ou a não promoção que se considera justa, levam a insatisfação e desinteresse pelo trabalho, a um mau relacionamento interpessoal e a absentismo. Dado que o nosso estudo não confirma esta afirmação, podemos especular que a integração e a prática institucional leva a que os sentimentos de insatisfação sejam baixos e ultrapassados.

Há uma correlação negativa entre duplo emprego e comportamento comunicacional assertivo total e com a equipa multidisciplinar. Confirma-se assim a hipótese levantada neste estudo. Já com 
os doentes, apesar de evidenciar diferenças, não são, do ponto de vista estatístico significativas. Quem tem duplo emprego apresenta com menos frequência comportamento comunicacional assertivo dentro da equipa multidisciplinar e no total. Estes dados vão ao encontro das investigações de Jenkins (1971), de Zohman (1973) e de House (1974) citado por Vaz Serra (2007) que revelaram que o número excessivo de horas de trabalho, ou a existência de dois trabalhos a tempo completo, estão associados a maior morbilidade e mortalidade. Vaz Serra (2007) refere que este tipo de comportamento não só se torna cansativo como priva o indivíduo do apoio e convívio social ou familiar que o podem compensar das tensões sentidas no trabalho. Queirós (2003) verificou que 35\% dos participantes referiam os relacionamentos no seio da equipa multidisciplinar como principal fonte de mal-estar/stress na sua vida profissional. Jesus e Amaro (2005, p. 28) referem que "é importante que os enfermeiros adquiram competências na área da comunicação assertiva, uma vez que através deste recurso comunicacional poderão estabelecer relações interpessoais mais satisfatórias e consequentemente mais frutíferas, sobretudo com os outros elementos da equipa multidisciplinar".

Há uma correlação positiva entre duplo emprego e controlo interno/externo dos problemas. Os enfermeiros que referem realizar trabalho duplo, apresentam menor controlo dos problemas ao contrário dos que não têm duplo emprego. Maslach et al. (2001) referem que a experiência de sobrecarga de trabalho e de pressão com o tempo apresenta-se em múltiplos estudos, com uma consistente e forte ligação ao burnout, especialmente na sua dimensão exaustão. Associado ao duplo emprego estão um conjunto de sinais e sintomas como a fadiga, irritabilidade, perda de controlo das situações e alterações comportamentais. Quem realiza trabalho duplo vê-se confinado às relações laborais. O tempo é pouco para as actividades com amigos, família e para com ele próprio. Quando há horários a cumprir e quando a responsabilidade implica com a vida de terceiros, a ansiedade é constante. Por exemplo, se um enfermeiro tem de ir trabalhar para determinado local e se está atrasado, está a implicar com a saída do seu colega que o aguarda para o render. Daí, o enfermeiro que realiza duplo emprego ter maior dificuldade em controlar os seus problemas do que os enfermeiros que só têm um emprego.

Há uma correlação positiva entre experiência profissional e o pedido de ajuda. Os enfermeiros com mais anos de profissão referem que pedem ajuda com maior frequência como uma estratégia de adaptação ao stress. Este dado pode sugerir que estes enfermeiros, como não percepcionam uma rede de apoio satisfatória, tenham de recorrer a esta estratégia quando se vêem numa situação problema.

Há uma correlação positiva entre experiência profissional e o confronto com o problema e planificação de estratégias. Os enfermeiros com mais anos de profissão referem confrontar o problema e delinear estratégias com maior frequência como adaptação ao stress. Silva (2005) chegou à conclusão no seu estudo que os enfermeiros com mais anos de idade, utilizam com mais frequência estratégias de coping de auto-controle. Refere ainda que os enfermeiros com menos anos no serviço, recorriam mais frequentemente a estratégias de resolução planeada do problema e os enfermeiros mais antigos utilizavam com mais frequência a estratégia de coping confrontativo.

Há uma correlação negativa entre experiência profissional e a dramatização da existência. Os enfermeiros com menos anos de profissão dramatizam mais a existência, tendo assim maior 
vulnerabilidade ao stresse referente a esta dimensão específica. O vínculo à instituição e as incertezas podem estar na origem destes resultados, embora não apareçam como determinantes nas variáveis estudadas. As expectativas, o confronto com a realidade e a dificuldade sentida na prestação de cuidados podem também indiciar esta relação encontrada. Delbrouk (2006, p.181) refere que "qualquer instituição que contrata pessoal clínico deveria considerar uma obrigação moral o facto de os iniciar e de os formar correctamente para o trabalho com os doentes". Estes factores podem determinar a necessidade de ter uma rede de apoio social maior, de modo a colmatar as suas dificuldades. Num estudo levado a cabo por Pedro Parreira (1998) com enfermeiros de oncologia, confirmou haver índices mais elevados de burnout quando há contacto com a morte. Atribui ainda à variável "idade" uma tendência explicativa da "despersonalização". Estes resultados podem sugerir o que foi referido anteriormente relativamente ao confronto com a realidade e dificuldades sentidas no trabalho.

Há correlação positiva entre experiência profissional e a subjugação. Os enfermeiros com mais anos de profissão referem uma maior subjugação que os enfermeiros com menos experiência profissional. Estes dados podem sugerir que os enfermeiros mais velhos, por uma questão cultural, enfatizam mais as hierarquias e daí resultar uma maior subjugação. No entanto não se pode afirmar que a subjugação aumenta com a idade, pois este estudo foi realizado num determinado momento, não sendo possível avaliar a evolução. Depreende-se daqui que os enfermeiros com maior experiência profissional apresentam uma média de subjugação mais elevada, mas que no passado esta pode ter sido maior e ter vindo a diminuir. É um dado que não se consegue obter neste estudo.

Há uma correlação negativa entre experiência profissional e a quantidade de apoio social percebido. Os enfermeiros com menos anos de profissão referem maior apoio social percebido que os com mais anos de profissão. Quanto à satisfação com o apoio percebido não se encontram resultados estatisticamente significativos. Como já foi referido anteriormente relativamente aos enfermeiros contratados, parte-se do princípio que são os mais novos, com menos anos de experiência profissional e daí a explicação ser a mesma, ou seja, ainda estão dependentes dos pais e contam com o seu apoio ao contrário dos enfermeiros mais velhos que apresentam outros encargos. Há ainda a questão dos enfermeiros deslocados geograficamente, que com a idade deixam de ter o apoio da família e contam simplesmente com amigos que geralmente coincidem com os colegas de trabalho.

Como limitações ao estudo referimos o número de enfermeiros que responderam ao questionário $(54,43 \%)$, pois uma amostra maior permitiria uma análise mais precisa das questões levantadas.

\section{Conclusões}

A realização deste estudo permitiu reforçar algumas afirmações já publicadas sobre o tema e ao mesmo tempo contrariar outras. Deve-se no entanto ter em conta o momento em que o estudo é realizado e a especificidade da população. A investigação com profissionais de saúde não se esgota, havendo sempre dados novos que demonstram interesse em ser estudados. 
O estudo do comportamento comunicacional assertivo foi preponderante nesta investigação. Os resultados obtidos foram ao encontro de estudos já realizados e serviram para comprovar a elevada frequência com que os enfermeiros adoptam comportamento comunicacional assertivo. Tal como noutras investigações, este é adoptado com mais frequência com os doentes do que no seio da equipa multidisciplinar, daí a assertividade ser essencial para o bom ambiente de trabalho e nas relações interpessoais. O estudo mostra que há um valor médio de realização pessoal alto e despersonalização baixo, reforçando a adopção de comportamentos assertivos com elevada frequência. A comunicação dentro da equipa é essencial para a satisfação profissional.

Um dado novo prende-se com a adopção de comportamento comunicacional assertivo e o facto de se ter um duplo emprego. Nesta situação, os enfermeiros que referem ter duplo emprego adoptam com menos frequência comportamento assertivo nas relações com a equipa, não se verificando diferença significativa no que respeita ao relacionamento com os doentes. Apresentam ainda maior dificuldade em controlar os seus problemas. Este é um resultado que poderá servir para novos estudos, centrados na sobrecarga de trabalho, relações interpessoais e qualidade de vida. Será importante perceber as causas que levam à procura do emprego duplo, uma vez que todos têm a noção do desgaste que lhe é inerente. O baixo salário, a falta de reconhecimento e o nível de vida mais caro pode sugerir esta opção.

o facto de trabalhar por turnos mostrou também o seu interesse no presente estudo, uma vez que revelou que quem faz turnos adopta com menos frequência comportamento comunicacional assertivo do que quem tem horário fixo. Os enfermeiros que trabalham por turnos estão sujeitos a maior desgaste, intolerância e perda de concentração.

A realização de muitos turnos seguidos pode influenciar a má prestação do enfermeiro e induzir o erro. É importante o descanso a seguir ao turno da noite e se possível, de acordo com a organização do enfermeiro chefe, atribuir no mínimo mais uma folga, de modo a haver uma recuperação física e psicológica que o profissional necessita.

A temática do burnout, ainda não está esgotada, apesar de bastante estudada. Neste estudo encontrámos resultados coincidentes com a bibliografia publicada, mas apresentámos também alguns dados novos e outros que não confirmam a bibliografia existente. Os homens apresentam um índice superior de despersonalização, mas também referem mais burnout e exaustão emocional que as mulheres. Em relação à realização profissional, as mulheres mostram-se mais satisfeitas que os homens. A característica de serviço não é relevante quanto ao burnout. Encontrou-se uma relação entre o estado civil de casado e valores mais baixos de burnout. Parece relevante o facto de se viver junto maritalmente para redução do stresse e adopção de estratégias que regulem a ansiedade. Os enfermeiros casados são os que referem recorrer com mais frequência a estratégias de adaptação ao stress, daí reforçar o baixo burnout encontrado.

Quanto à vulnerabilidade ao stress, o estudo sugere que os enfermeiros mais novos são mais propensos, ressaltando deste resultado o facto da pouca autonomia, do vínculo precário, da incerteza e insegurança. Estes enfermeiros recorrem com mais frequência a estratégias de adaptação ao stress que passam por planear as acções antes de agir, reforçando o que foi dito anteriormente. Como seria 
de esperar, referem ainda uma percepção de apoio social superior aos enfermeiros mais velhos. O facto de a maior parte destes enfermeiros estar ainda dependente dos pais, faz com que percepcionem ter mais apoio. A experiência profissional parece ser importante no que diz respeito à vulnerabilidade ao stresse e ao confronto com os problemas. Esta é uma questão que poderá ser melhor estudada no sentido da autonomia e estabilidade de emprego.

Deste estudo sobressaem variáveis que poderão ser aprofundadas em estudos posteriores, como é o caso do trabalho por turnos, o vínculo à instituição, o duplo emprego e a experiência profissional. O estudo do comportamento comunicacional assertivo e do burnout não se esgota e será importante replicar este estudo noutras instituições, noutros pontos geográficos e com um número maior de enfermeiros. A preocupação com bem-estar dos profissionais de saúde passa não só pelas instituições mas também a nível governamental. A integração dos novos profissionais é essencial e a formação extensiva a todos os enfermeiros parece ser importante para a adopção de uma filosofia de trabalho comum, onde não sejam evidentes diferenças no cuidar. A questão de segurança do contrato parece ser bastante relevante.

A criação de espaços de debate, acordos com ginásios e a realização de actividades lúdicas que envolvam os profissionais, podem ser algumas das medidas que facilitem a redução do stress e situações de burnout. O reforço da adopção do comportamento comunicacional assertivo e da satisfação profissional, é importante uma vez que é necessário cuidar de quem cuida.

\section{Bibliografia}

DelbroucK, M. (2006) - Sindrome de EXaustão (Burnout). Lisboa, Climepsi editores. $1^{\circ}$ ed. ISBN 972-796-228-9.

FORTIN, MARIE-FABIENNE (1999) - O PROCESSO dE INVESTIGAÇÃO. LOURES: LUSOCIÊNCIA,. ISBN 972-8383-10-X.

GARCIA, I. M. (1990). BURNOUT EN PROFESORES Y MARGINACIÓN SOCIAL: DIFERENCIAS EN UNA MUESTRA DE PROFESORES DE CENTROS educativos marginado y no marginados. Em Livro de Comunicaciones del III Congreso Nacional de Psicología Social. Santiago de Compostela: TórCulo A.G.

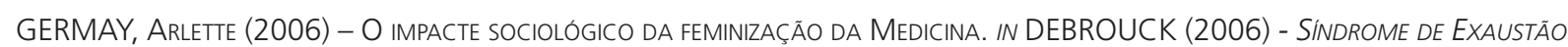
(BURNout). LISBOA, CLIMEPSI EDITORES. $1^{\circ}$ ED. ISBN 972-796-228-9. P.214

HESBEEN, WALTER (2000) - CUIDAR NO HOSPITAL: ENQUADRAR OS CUIDADOS DE ENFERMAGEM NUMA PERSPECTIVA DE CUIDAR. LOURES. LUSOCIÊNCIA, ISBN 972-8383-11-8.

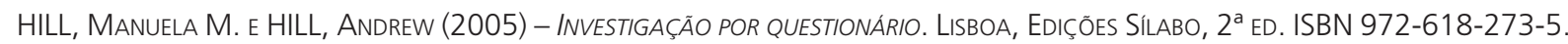

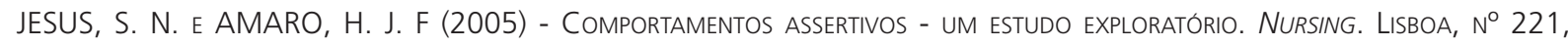
(MAIO). P. 24-28.

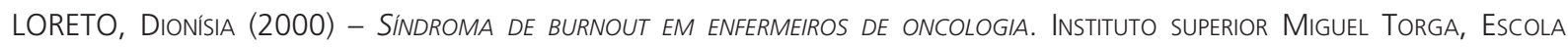
SUPERIOR DE ALTOS ESTUdos, TeSe de MESTRAdo

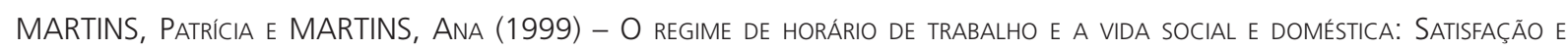
eStRATÉGIAS DE COPING - UM ESTUdO NUMA AMOSTRA DE ENFERMEIROS. ANÁlISE PSICOLÓGICA, 3 (XVII); 529-546

MASLACH, C. E JACKSON, S.E. (1981) - THE INCOSUREMENT OF EXPERIENCED BURNOUT. JOURNAL OF OCCUPATION BEHAVIOUR, 2, 99-113 maslach, C., JaCKSON, S. E. e Leiter, M. P. (1986) - The Maslach Burnout Inventory (3rd ed.). Palo Alto, CA: Consulting Psychologists Press. 
MASLACH, C e ReEVy, G. M., (2001). People's use of social support: Gender and personality differences. Sex Roles, 44, 437-459.

Mendes, Rene(1995) - Patologia do Trabalho. Rio de Janeiro: Ateneu,

PACHECO, José E JESUS, SAUL (2007) - BURNOUt E COPING EM PROFISSIONAIS DE SAÚdE. REVISTA DE INVESTIGAÇÃO EM ENFERMAGEM, $N^{\circ} 16,32-41$, ISSN 0874-7695

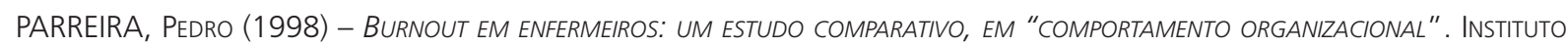
superior de Psicologia Aplicada. Tese de Mestrado. Lisboa

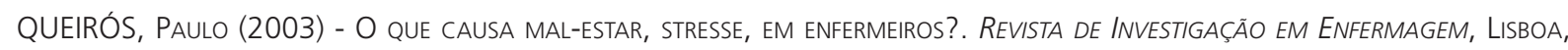
$\left(N^{\circ} 8\right)$, P. 3-7

Queirós, Paulo (2004) - Burnout no trabalho e conjugal em Enfermeiros Portugueses. Tese de Doutoramento não publicada. Extremadura: Departamento de Psicologia e Sociologia da Educação.

relvas, Ana Paula (1996) o Ciclo Vital da Famíla. Porto: Ediçōes Afrontamento

SARASON, I.; SARAsOn, B. e PIERCE, G., (1987); Versão portuguesa de Pinheiro, M. \& Ferreira, J. (2000) - Questionário de APOIO SOCIAL (SSQ).

SILVA, ELSA (2005) - StreSSE E ESTRATÉGIAS de COPING EM ENFERMEIROS. REVISTA DE INVESTIGAÇÃO EM ENFERMAGEM. No 11. 46-53, ISSN 0874-7695

TALBOT Y, CHRISTIE-SEELY J, CHARBONNEAU S. (1984) - THE FAMILY CYCLE - ITS IMPORTANCE IN WORKING WITH FAMILIES. IN: Christie-Seely J, editor. Working With the Family in Primary Care: A Systems Approach to Health and Illness. New York: Praegen;. P. 32-60.

VAZ SerRa, A. (1988) - Um estudo sobre coping, O inventário de Resolução de Problemas. Psiquiatria clínica - 9 (4), $303-$ $-315$.

VAZ SERRA, A. (2000) - A Vulnerabilidade aO Stresse. Psiquiatria ClínICA, 21, (4) pp. 261-278

VAZ SerRA, A. (2007) - O StresSe na Vida de todos os dias. Coimbra: Adriano Vaz Serra, $3^{\mathrm{a}}$ edição. 